\title{
Trend in the development of oil palm fruit harvesting technologies in Malaysia
}

\begin{abstract}
Harvesting oil palm fresh fruit bunches (FFB) on tall oil palm trees is a laborious and hazardous task. Lately, with the escalating problem of labor shortage, the exigent demand to mechanize the harvesting task cannot be overlooked. Over the years, many harvesting methods and technologies have been used and developed to increase the harvesting productivity. This paper reviews the conventional manual harvesting using manual labor, mechanization of harvesting task using harvesting machines as well as research on climbing robots for harvesting FFB in Malaysia. In essence, it provides an overview of the trend in the development of harvesting technologies in Malaysia. Realizing the potential of climbing robots for harvesting, the morphological structures and physical characteristics of oil palm trunks in its natural surroundings are examined closely to identify the challenges in the climbing and harvesting processes. Next, a set of design criteria is introduced to overcome those challenges. In addition, several mechanisms are proposed which play integral parts in enhancing the climbing and harvesting tasks.
\end{abstract}

Keyword: Oil palms fresh fruit bunches; Manual harvesting; Harvesting machines; Tree climbing robots; Mechanization in harvesting 